\title{
Evaluation of factors affecting the sense of coherence in women during pregnancy: A prospective pilot study
}

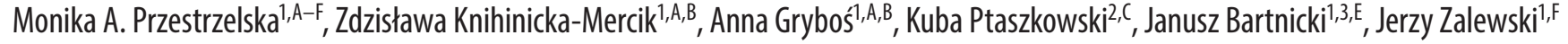 \\ ${ }^{1}$ st Department and Clinic of Gynecology and Obstetrics, Faculty of Health Sciences, Wroclaw Medical University, Poland \\ 2 Department of Clinical Biomechanics and Physiotherapy in Motor System Disorders, Faculty of Health Sciences, Wroclaw Medical University, Poland \\ ${ }^{3}$ Department of Gynecology and Obstetrics, Hospital Märkisch-0derland GmbH, Strausberg, Germany \\ A - research concept and design; $\mathrm{B}$ - collection and/or assembly of data; $\mathrm{C}$ - data analysis and interpretation; \\ $\mathrm{D}$ - writing the article; $\mathrm{E}$ - critical revision of the article; $\mathrm{F}$ - final approval of the article
}

Address for correspondence

Monika A. Przestrzelska

E-mail:monika.przestrzelska@umed.wroc.pl

\section{Funding sources}

The project was funded by the Wroclaw Medical University allocated on the basis of the decision number ST-793.

Conflict of interest None declared

Received on January 8, 2017 Reviewed on March 16, 2017 Accepted on May 15, 2017

\section{Abstract}

Background. Pregnancy is a special time in the life of a woman, which induces many changes not only in the biological, but also in the biopsychosocial dimension.

Objectives. The aim of the study was to evaluate the factors affecting the sense of coherence (SOC) among women during pregnancy. It was hypothesized that a high SOC will depend on a high level of received support, lack of the risk of mental disorders in the perinatal period and physiological course of pregnancy.

Material and methods. Factographic material was collected by a diagnostic survey method. As a $1^{\text {st }}$ research tool, the Polish adaptation of the Sense of Coherence - Orientation to Life Questionnaire (SOC-29) was used. Another research tool was the Edinburgh Postnatal Depression Scale (EPDS), used here for pregnant women and therefore called Edinburgh Depression Scale (EDS).

Results. We analyzed the data of all 200 women with physiological pregnancies and 200 women with complicated pregnancies from whom a complete valid responses were obtained. All women were aged between 18 and 36 years. Significant predictors of low SOC results in the model were: age (odd ratio $(O R)=0.929,95 \%$ confidence interval (Cl): $0.870-0.992, p=0.0280)$, being multipara ( $O R=1.996$, $95 \%$ Cl: 1.271-3.135, $p=0.0027)$, having never/occasionally husband/partner support ( $O R=1.978$, $95 \%$ (l: $1.070-3.656, p=0.0295)$, and EDS results (OR $=1.312,95 \%$ (l: $1.169-1.472, p=0.0000)$.

Conclusions. Predisposing factors for the occurrence of a low rate of $\mathrm{SOC}$ in pregnant women are: lower age, multiparity, lack of social support, especially from the husband/partner, and the risk of depression during pregnancy. This may result from the fact that a strong SOC develops in the process of socialization, and with age we acquire the ability to accurately assess reality.

Key words: depression, pregnancy, coherence, social support

DOI

10.17219/acem/73802

\section{Copyright}

Copyright by Author(s)

This is an article distributed under the terms of the

Creative Commons Attribution Non-Commercial License

(http://creativecommons.org/licenses/by-nc-nd/4.0/) 


\section{Introduction}

The time directly following birth is not deprived of negative emotions, which can hinder the childcare. This period is usually short-lasting, but when it is prolonged, postpartum depression (PPD) cannot be excluded. Psychosocial factors, in addition to personality, determine the occurrence of this condition to a large extent. Among the 13 potential causes of PPD, Beck indicated low selfesteem, anxiety in the prenatal period and stressful life experiences. ${ }^{1}$ Since the effects resulting from the symptoms of the disease can be both short- and long-term, their influence on maternal bonding with the child should be considered. $^{2}$

A tool used to identify the risk of PPD is the Edinburgh Postnatal Depression Scale (EPDS). The authors of EPDS and the British Journal of Psychiatry own the copyright to this tool and they allow its use for scientific purposes. ${ }^{3}$ This questionnaire is characterized by high sensitivity and specificity. Validation performed in the group of women outside the period of postpartum allowed us to demonstrate this tool to pregnant women as the Edinburgh Depression Scale (EDP). ${ }^{4}$

In the concept of salutogenesis, Antonowsky emphasizes the importance of global life orientation, known as a sense of coherence (SOC), which allows the individual to function in the bio-psycho-social dimension in an organized manner. Such an individual perceives reality as understandable, manageable and meaningful. These $3 \mathrm{com}-$ ponents, according to Antonowsky, determine the optimal mobilization of defense mechanisms in an effort to avoid confrontation with the stressor. The $1^{\text {st }}$ component, the sense of comprehensibility, determines the fact that the stimuli from internal and external environment are organized and can be logically explained. The $2^{\text {nd }}$ component of the SOC, the sense of manageability, allows us to meet the demands which are conditioned by the stimuli. The $3^{\text {rd }}$ component, the sense of meaningfulness, indicates that it is worth getting involved and act to meet the requirements. This ability is related to the essence of the concept of coherence - a SOC. ${ }^{5-7}$

Support is one of the most important elements of human life. During pregnancy the need of support increases to a large extent. Especially important is the social stability based on the emotional and instrumental support, which has significant meaning in the formation of the bond between mother and her unborn child. ${ }^{8}$ Psychological comfort of a pregnant woman in the aspect of the development of this relationship is of irreplaceable importance. The lack of support from the husband/partner during the pregnancy as well as after the birth has a negative impact on the selfesteem in women. ${ }^{9}$ Emotional support, especially in a situation of high stress levels, can counteract depression. It encourages taking pro-health actions and, therefore, it can eliminate harmful behavior not only in a biological, but also in a psycho-social dimension. ${ }^{10}$

\section{Objectives}

The aim of the study was to evaluate the factors affecting the SOC among women during pregnancy. It was hypothesized that a high SOC will depend on a high level of received support, the lack of risk of mental disorders in the perinatal period and physiological course of pregnancy.

\section{Material and methods}

Factographic material was collected by a diagnostic survey method. As a $1^{\text {st }}$ research tool, the Polish adaptation of the Sense of Coherence - Orientation to Life Questionnaire (SOC-29) was used to assess the level of the SOC. The $2^{\text {nd }}$ research tool was the EPDS in a version designated as the EDS. The $3^{\text {rd }}$ tool was the personal questionnaire assessing the type and extent of social support received by pregnant women. Questionnaires were distributed to pregnant women during antenatal classes, in primary care units and at the Pathology of Pregnancy Ward of $1^{\text {st }}$ Department and Clinic of Gynecology and Obstetrics at the Wroclaw Medical University, Poland. Women were advised that participation in the study was voluntary and anonymous. The study received a positive opinion of the Bioethics Committee of the Wroclaw Medical University, Poland (KB-655/2014).

The target group consisted of pregnant women. The inclusion criteria involved obtaining an informed consent to participate in the study, the duration of pregnancy equal to or above 30 weeks, physiological or complicated course of pregnancy and age under 40 years. The exclusion criteria included the lack of consent to participate in the study, life-threatening condition to the mother and/or child, gestational age below 30 weeks, age 40 years and above, and chronic illness diagnosed before pregnancy, with particular emphasis on mental disorders.

The SOC-29 questionnaire consists of 29 questions that relate to the 3 components of SOC: comprehensibility (11 questions), manageability (10 questions) and meaningfulness (8 questions). The respondent answers each question by marking the answer on a scale from 1 to 7 , where 7 is the maximum intensity of the characteristics associated with 1 of the 3 dimensions of SOC. The results are calculated by summing the obtained points. The higher the score, the higher the SOC. A score over 156 points indicates a high SOC, a result below 156 points indicates a low SOC.

The EDS scale consists of 10 questions. Each woman chooses 1 of 4 possible answers corresponding to her feelings in the last 7 days. A score of 12 points and above (out of a max. 30 points possible) may suggest the probability of depressive disorders of varying severity.

The personal questionnaire also consisted of 10 questions. The questionnaire covered basic information about the participant of the study (the woman's age, duration 
of pregnancy, type of pregnancy complications, and the type and extent of social support received by the pregnant woman).

\section{Statistical analysis}

All analyses were performed using STATISTICA v. 12.4 software (StatSoft Inc., Tulsa, USA). Results are presented as mean, median, minimum, and maximum results and standard deviation (SD) or percentages. Participants were divided into subgroups according to Sense of Coherence Scale (low SOC vs high SOC). Normality of distribution was assessed using the Shapiro-Wilk test. The $X^{2}$ test or the Mann-Whitney U test were used (where appropriate) to compare subgroups. Multivariate forward logistic regression analysis using the stepwise method included factors potentially favoring the occurrence of a low SOC: age, pregnancy (physiological vs complicated), parity (primipara/multipara), husband/partner support (never/occasionally vs often/ always), family support (never/occasionally vs often/always), medical staff support (never/occasionally vs often/always), and EDS (in points). Odds ratios (OR) are presented with $95 \%$ confidence intervals (CI). The fit of the regression model was assessed with the HosmerLemeshow test. The results were considered significant with a p-value $<0.05$.

\section{Results}

\section{Characteristics of the group}

We analyzed the data of all 400 respondents (200 women with physiological pregnancy and 200 women with complicated pregnancy) from whom complete and valid responses were obtained. The characteristics of the participants are displayed in Table 1 . It shows that $50 \%$ of the participants were primipara, $84.8 \%$ had often/always husband/partner support, $52 \%$ had often/always family support and $80.2 \%$ had often/always medical staff support. All women were aged between 18 and 36 years.

Results of the logistic regression are shown in Table 2. They showed that parity was associated with SOC $(\mathrm{OR}=1.67(1.12-2.49))$, husband/partner support $(\mathrm{OR}=2.56(1.46-4.48))$ and EDS $(\mathrm{OR}=1.35(1.21-1.51))$.

Results of the multiple logistic regression of Sense of Coherence Scale are shown in Table 3. The goodness of fit statistics (Hosmer-Lemeshow test, $\mathrm{p}=0.3661$ ) indicated a satisfactory fit for the model. Significant predictors of low SOC results in the model were: age $(\mathrm{OR}=0.929,95 \% \mathrm{CI}$ : $0.870-0.992, \mathrm{p}=0.0280)$, being multipara $(\mathrm{OR}=1.996$, 95\% CI: $1.271-3.135, \mathrm{p}=0.0027)$, having never/occasionally husband/partner support $(\mathrm{OR}=1.978,95 \% \mathrm{CI}$ : $1.070-3.656, \mathrm{p}=0.0295)$, and EDS results $(\mathrm{OR}=1.312$, 95\% CI: $1.169-1.472, \mathrm{p}=0.0000)$.

\section{Discussion}

Pregnancy is a special time in the life of woman, which induces many changes not only in the biological, but also in the biopsychosocial dimension. Psychologists classify it as a critical life event. In the Social Readjustment Rating Scale (SRRS) created by Holmes and Rahe, pregnancy occurs between other stressors with 40 out of 100 possible points. ${ }^{11}$

Although studies indicate that up to $80 \%$ of women experience mood swings during pregnancy and after childbirth, only a few researchers undertook the problem. ${ }^{12}$ The emotions experienced by a pregnant woman result from conscious or unconscious evaluation of a new life situation. The symptoms of depression are diagnosed in about 15\% of pregnant women and $13 \%$ of mothers within the $1^{\text {st }}$ 6 months after the birth. ${ }^{13-17}$ The impact of the emotional state of a woman, not only on the fetus but also on the infant, is an important issue. Identification of emotional disorders during pregnancy is particularly relevant in terms of health and safety of the newborn. ${ }^{18,19}$ McFarland et al. showed that clinically diagnosed depression during pregnancy affects the "maternal-fetal attachment". ${ }^{20}$ The authors indicate that this condition causes the abnormal relations between the mother and child and may affect its development. ${ }^{18-20}$

The predictors of PPD are presented by many authors. In particular, they emphasize the occurrence of depression in a previous pregnancy, low self-esteem, stress during pregnancy, lack of social support, unplanned/unwanted pregnancy, and low socioeconomic status. ${ }^{16,21-25}$

Considering the fact that threatened pregnancy is a significant source of emotional strain, it is likely that the stress will be at a considerably higher level. Lewicka et al.,

Table 1. Characteristic of the group

\begin{tabular}{|c|c|c|}
\hline \multicolumn{3}{|c|}{ Characteristic of the group $(n=400)$} \\
\hline \multicolumn{2}{|l|}{ Age [years] } & $\begin{array}{c}\text { mean }=27.4 \\
\text { median }=27.0 \\
\text { min- } \max =18.0-36.0 \\
\mathrm{SD}=3.5\end{array}$ \\
\hline \multirow{2}{*}{ Pregnancy } & physiological & $n=200(50 \%)$ \\
\hline & complicated & $n=200(50 \%)$ \\
\hline \multirow{2}{*}{ Parity } & primipara & $n=200(50 \%)$ \\
\hline & multipara & $n=200(50 \%)$ \\
\hline \multirow{2}{*}{$\begin{array}{l}\text { Husband/partner } \\
\text { support }\end{array}$} & never/occasionally & $n=61(15.3 \%)$ \\
\hline & often/always & $\mathrm{n}=339(84.8 \%)$ \\
\hline \multirow{2}{*}{ Family support } & never/occasionally & $n=192(48 \%)$ \\
\hline & often/always & $\mathrm{n}=208(52 \%)$ \\
\hline \multirow{2}{*}{$\begin{array}{l}\text { Medical staff } \\
\text { support }\end{array}$} & never/occasionally & $n=79(19.8 \%)$ \\
\hline & often/always & $\mathrm{n}=321(80.2 \%)$ \\
\hline \multicolumn{2}{|c|}{ Edinburgh Depression Scale [points] } & $\begin{array}{c}\text { mean }=6.5 \\
\text { median }=6.0 \\
\text { min- } \max =4.0-14.0 \\
\mathrm{SD}=2.1\end{array}$ \\
\hline
\end{tabular}

SD - standard deviation. 
evaluating the intensity of fear in a group of pregnant women hospitalized in the department of pathology of pregnancy, showed that it was at the secondary level. Only $0.98 \%$ of the women experienced a serious exacerbation of anxiety. ${ }^{26}$

In this study, a comparative analysis between 2 groups of pregnant women (physiological and complicated course of pregnancy, $\mathrm{n}=200$ vs $\mathrm{n}=200$ ) showed no statistically significant differences between the EDS results ( $\mathrm{p}>0.4678$ ). In the study groups the quality of pregnancy is, therefore, not a risk exponent of depressive disorders in perinatal period. Both groups also showed no statistically significant difference in SOC ( $p>0.0546)$. Nevertheless, the group of pregnant women with a low SOC achieved higher EDS score $(\mathrm{OR}=1.312)$. Other studies demonstrated that the SOC is a strong predictor of well-being both in pregnancy and in the postnatal period, and that it can make a meaningful difference in the clinical, holistic women's health care.
The study also emphasizes the value of, subjective evaluation of pregnant women in terms of needed support, conducted by the midwife. ${ }^{27}$ The deficit of social support, especially the lack of support from the husband/partner in studied group of women, was noticeably correlated with a low SOC. Two times more women who reported the lack of husband's/partner's support had a low SOC than women who reported obtained support $(\mathrm{OR}=1.978)$; the result was statistically significant $(\mathrm{p}<0.0295)$. Psychological comfort of the pregnant woman in the aspect of the development of partner bond is an undeniable fact. The lack of support from a partner during pregnancy and after childbirth has a negative impact on self-esteem in women. ${ }^{9}$

An important factor influencing the positive emotions in pregnant women is the support offered to the woman by the partner before the birth and a declaration of support after the birth, especially in the participation in childcare. ${ }^{28}$ The lack of support, especially the partner support,

Table 2. Results of the logistic regression of Sense of Coherence Scale (SOC)

\begin{tabular}{|c|c|c|c|c|c|}
\hline \multirow{2}{*}{\multicolumn{2}{|c|}{ Variable }} & \multicolumn{2}{|c|}{ Sense of Coherence Scale (SOC) } & \multirow{2}{*}{ p-value } & \multirow{2}{*}{ OR $(95 \% \mathrm{Cl})$} \\
\hline & & low SOC $(n=171)$ & high SOC $(\mathrm{n}=229)$ & & \\
\hline \multicolumn{2}{|l|}{ Age [years] } & $\begin{array}{c}\text { mean }=27.1 \\
\text { median }=27.0 \\
\text { min-max }=18.0-36.0 \\
\mathrm{SD}=3.6\end{array}$ & $\begin{array}{c}\text { mean }=27.6 \\
\text { median }=27.0 \\
\text { min- } \max =19.0-34.0 \\
\mathrm{SD}=3.3\end{array}$ & 0.1285 & $0.96(0.90-1.01)$ \\
\hline \multirow{2}{*}{ Pregnancy } & complicated & $n=84(49.1 \%)$ & $n=116(50.7 \%)$ & \multirow{2}{*}{0.7617} & $0.94(0.63-1.41)$ \\
\hline & physiological & $n=87(50.9 \%)$ & $n=113(49.3 \%)$ & & 1.000 \\
\hline \multirow{2}{*}{ Parity } & multipara & $n=98(57.3 \%)$ & $n=102(44.5 \%)$ & \multirow{2}{*}{0.0118} & $1.67(1.12-2.49)$ \\
\hline & primipara & $n=73(42.7 \%)$ & $n=127(55.5 \%)$ & & 1.000 \\
\hline \multirow{2}{*}{ Husband/partner support } & never/occasionally & $n=38(22.2 \%)$ & $n=23(10.0 \%)$ & \multirow{2}{*}{0.0010} & $2.56(1.46-4.48)$ \\
\hline & often/always & $n=133(77.8 \%)$ & $n=206(90 \%)$ & & 1.000 \\
\hline \multirow{2}{*}{ Family support } & never/occasionally & $n=82(48 \%)$ & $n=110(48 \%)$ & \multirow{2}{*}{0.9871} & $0.99(0.67-1.48)$ \\
\hline & often/always & $\mathrm{n}=89(52 \%)$ & $n=119(52 \%)$ & & 1.000 \\
\hline \multirow{2}{*}{ Medical staff support } & never/occasionally & $n=34(19.9 \%)$ & $n=45(19.7 \%)$ & \multirow{2}{*}{0.9539} & $1.02(0.62-1.67)$ \\
\hline & often/always & $n=137(80.1 \%)$ & $n=184(80.3 \%)$ & & 1.000 \\
\hline \multicolumn{2}{|c|}{ Edinburgh Depression Scale [points] } & $\begin{array}{c}\text { mean }=7.2 \\
\text { median }=7.0 \\
\text { min- } \max =4.0-14.0 \\
\mathrm{SD}=2.6\end{array}$ & $\begin{array}{c}\text { mean }=6.0 \\
\text { median }=6.0 \\
\text { min- } \max =4.0-11.0 \\
S D=1.4\end{array}$ & 0.0000 & $1.35(1.21-1.51)$ \\
\hline
\end{tabular}

SD - standard deviation; OR - odds ratio; $\mathrm{Cl}$ - confidence interval.

Table 3. Results of the multiple logistic regression of Sense of Coherence Scale (SOC)

\begin{tabular}{|c|c|c|c|c|c|c|c|}
\hline \multicolumn{8}{|c|}{ Sense of Coherence Scale (low SOC) } \\
\hline \multicolumn{2}{|c|}{ Variables* } & $\begin{array}{c}\text { regression } \\
\text { coefficients (B) }\end{array}$ & SE & OR & $95 \% \mathrm{Cl}$ lower & $95 \% \mathrm{Cl}$ upper & $p$-value \\
\hline \multicolumn{2}{|l|}{ Age } & -0.073 & 0.033 & 0.929 & 0.870 & 0.992 & 0.0280 \\
\hline Parity & multipara & 0.691 & 0.230 & 1.996 & 1.271 & 3.135 & 0.0027 \\
\hline Husband/partner support & never/occasionally & 0.682 & 0.313 & 1.978 & 1.070 & 3.656 & 0.0295 \\
\hline \multicolumn{2}{|l|}{ EDS } & 0.272 & 0.059 & 1.312 & 1.169 & 1.473 & 0.0000 \\
\hline
\end{tabular}

OR - odds ratio, Cl - confidence interval; SE - standard error; EDS - Edinburgh Depression Scale.

* Only significant variables are shown from the variables entered: age [years], pregnancy (physiological vs complicated), parity, husband/partner support (never/occasionally vs often/always), family support (never/occasionally vs often/always), medical staff support (never/occasionally vs often/always), Edinburgh Depression Scale (EDS) [points]. 
is of particular importance in the case of an unwanted pregnancy. In addition, these women may be exposed to psychosocial stressors, which may increase the level of depressive symptoms and also reduce general life satisfaction. ${ }^{29-31}$ The relationship between the social support and the risk of PPD has been studied by many researchers. Morikawa et al. in cohort studies showed that postpartum women with a low level of social support had a significantly higher risk of depression than those who received support in line with their expectations. ${ }^{32}$ These results suggest a protective effect of social support, particularly from the husband/partner, as a prevention of depressive disorders during pregnancy and the postpartum period. Thus, the need to identify mothers with a low level of support, as they are at increased risk of PPD, gains special importance. Understanding the relationship and the role of social support during pregnancy and after birth also becomes crucial. ${ }^{33}$

Taking into account the fact that the presented study showed the correlation of a low SOC with the risk of depression, the age of women was also considered in this group. We observed that the lower age of women conduces the lower result of SOC ( $\mathrm{p}<0.0280)$. This is confirmed by the results of other authors. Especially teenage mothers compared with older women are more prone to mood disorders, including depression during the postpartum period. This problem affects $26 \%$ of young mothers, which is 2 times more often compared to the result for the general population of $13 \%$. It should be mentioned that possible emotional immaturity to motherhood can significantly affect the pregnant adolescent. ${ }^{34,35}$

The lack of support from the partner is not only expressed by his absence or lack of interest. Ludermir et al. proved that psychological abuse against a woman strongly correlates with PPD, both in cases of physical and sexual abuse. ${ }^{36}$ They studied 1,045 women using the EPDS. The risk of depression was identified in $26 \%$ of the respondents, of which $28 \%$ reported being abused by their partner. Also, the study showed that women experiencing psychological violence were 2 times more often exposed to the occurrence of PPD. About $10 \%$ of all cases of PPD are related to women who have experienced mental abuse from their partners. ${ }^{36}$

In the group with a low SOC, we also analyzed the women's parity. Multiparous women 2 times more often obtained a low SOC score compared to the primiparous $(\mathrm{OR}=1.996)$; the result was statistically significant ( $\mathrm{p}<0.0027)$. The researchers are not unanimous regarding the influence of parity on the SOC or depression. Particularly, the parity is not an unambiguous risk factor for depression, since both primiparity and multiparity are indicated as risk factors for this disorder. ${ }^{37-40}$ Therefore, a correlation with different factors seems to have a higher predictive value. It should be assumed that the low rate of SOC may be an important predictor in a multifaceted analysis of the risk of emotional disorders in women, not only in the postpartum period, but also during the pregnancy.

\section{Conclusions}

Predisposing factors for the occurrence of a low rate of SOC in pregnant women are: lower age, multiparity, lack of social support (especially from the husband/partner) and the risk of depression during pregnancy. It may result from the fact that a strong SOC develops in the process of socialization, and with age we acquire the ability to accurately assess reality. Social support is one of the most important aspects of human life. As social beings, in order to achieve an optimal biopsychosocial development, which is the paradigm of health, we need the help of others, especially loved ones.

\section{References}

1. Beck CT. A meta-analysis of predictors of postpartum depression. Nurs Res. 1996;45(5):297-303.

2. Kossakowska K. Prevention of postpartum depression - the role of health professionals in identifying risk factors and symptoms of the disease [in Polish]. Medycyna Ogólna i Nauki o Zdrowiu. 2013;19(4):463-468.

3. Cox JL, Holden JM, Sagovsky R. Detection of postnatal depression. Development of the 10-item Edinburgh Postnatal Depression Scale. Br J Psychiatry. 1987;150:782-786.

4. Borysewicz K. The Edinburgh Postnatal Depression Scale [in Polish]. Postepy Psychiatr Neurol. 2000;9:71-77.

5. Antonovsky, A. Health, Stress and Coping. San Francisco, CA: JosseyBass; 1997.

6. Antonovsky A. Unraveling the Mystery of Health: How People Manage Stress and Stay Well. $1^{\text {st }}$ ed. San Francisco, CA: Jossey-Bass; 1987:34-45.

7. Eriksson M, Lindström B. Antonovsky's sense of coherence scale and the relation with health: A systematic review. J Epidemiol Community Health. 2006;60(5):376-381.

8. Glazier RH, Elgar FJ, Goel V, Holzapfel S. Stress, social support, and emotional distress in a community sample of pregnant women. J Psychosom Obstet Gynaecol. 2004;25(3-4):247-255.

9. Maçola L, do Vale IN, Carmona EV. Assessment of self-esteem in pregnant women using Rosenberg's Self-Esteem Scale [in Portuguese]. Rev Esc Enferm USP. 2010;44(3):570-577.

10. Bielawska-Batorowicz E. High risk pregnancy. In: Psychological Aspects of Procreation. Katowice, Poland: Wydawnictwo Naukowe "Śląsk"; 2006:153-182.

11. Holmes $\mathrm{TH}, \mathrm{Rahe} \mathrm{RH}$. The social readjustment rating scale. J Psychosom Res. 1967;11(2):213.

12. Rymaszewska J, Dolna M, Gryboś M, Kiejna A. Mental disorders during pregnancy and postpartum period: Epidemiology, etiology, classification and treatment [in Polish]. Ginekol Pol. 2005;74(4):321-330.

13. Dietz P, Williams SB, Callaghan WM, Bachman DJ, Whitlock EP, Hornbrook MC. Clinically identified maternal depression before, during, and after pregnancies ending in live births. Am J Psychiatry. 2017;164(10):1515-1520.

14. Cox JL, Murray D, Chapman G. A controlled study of the onset, duration and prevalence of postnatal depression. Br J Psychiatry. 1993;163:27-31.

15. Gavin NI, Gaynes BN, Lohr KN, Meltzer-Brody S, Gartlehner G, Swinson T. Perinatal depression: A systematic review of prevalence and incidence. Obstet Gynecol. 2005;106(5 Pt 1):1071-1083.

16. Robertson E, Grace S, Wallington T, Stewart DE. Antenatal risk factors for postpartum depression: A synthesis of recent literature. Gen Hosp Psychiatry. 2004;26(4):289-295.

17. Kettunen $\mathrm{P}$, Koistinen $\mathrm{E}$, Hintikka J. Is postpartum depression a homogenous disorder: Time of onset, severity, symptoms and hopelessness in relation to the course of depression. BMC Pregnancy Childbirth. 2014;14:402.

18. Tharner A, Luijk MP, van ljzendoorn MH, et al. Maternal lifetime history of depression and depressive symptoms in the prenatal and early postnatal period do not predict infant-mother attachment quality in a large, population-based Dutch cohort study. Attach Hum Dev. 2012;14(1):63-81. 
19. Pinto TM, Caldas F, Nogueira-Silva C, Figueiredo B. Maternal depression and anxiety and fetal-neonatal growth. $J$ Pediatr (Rio J). 2017:93(5):452-459.

20. McFarland J, Salisbury AL, Battle CL, Hawes K, Halloran K, Lester BM. Major depressive disorder during pregnancy and emotional attachment to the fetus. Arch Womens Ment Health. 2011;14(5):425-34.

21. Li Y, Long Z, Cao D, Cao F. Social support and depression across the perinatal period: A longitudinal study. J Clin Nurs. 2017;26(17-18): 2776-2783.

22. Kinsella MT, Monk C. Impact of maternal stress, depression \& anxiety on fetal neurobehavioral development. Clin Obstet Gynecol. 2009;52(3):425-440.

23. Beck CT. Predictors of postpartum depression: An update. Nurs Res. 2001;50(5):275-285.

24. Silverman ME, Reichenberg A, Savitz DA, et al. The risk factors for postpartum depression: A population-based study. Depress Anxiety. 2017;34(2):178-187.

25. O'Hara MW, Swain AM. Rates and risk of postpartum depression and meta-analysis. Int Rev Psychiatry. 1996;8(1):37-54.

26. Lewicka M, Wdowiak A, Sulima M, Wójcik M, Makara-Studzińska M. Evaluation of negative emotions using the DASS scale in a group of pregnant women hospitalized in the department of pregnancy pathology [in Polish]. Problemy Higieny i Epidemiologii. 2013;94(3): 459-464.

27. Sjöström $H$, Langius-Eklöf $A$, Hjertberg R. Well-being and sense of coherence during pregnancy. Acta Obstet Gynecol Scand. 2004;83(12):1112-1118

28. Pięta B, Jurczyk MU, Wszołek K, Opala T. Emotional changes occurring in women in pregnancy, parturition and lying-in period according to factors exerting an effect on a woman during the peripartum period. Ann Agric Environ Med. 2014;21(3):661-665.

29. Dibaba Y, Fantahun M, Hindin MJ. The association of unwanted pregnancy and social support with depressive symptoms in pregnancy: Evidence from rural southwestern Ethiopia. BMC Pregnancy Childbirth. 2013;13:135.

30. Lancaster CA, Gold KJ, Flynn HA, Yoo H, Marcus SM, Davis MM. Risk factors for depressive symptoms during pregnancy: A systematic review. Am J Obstet Gynecol. 2010;202(1):5-14.

31. Gipson JD, Koenig MA, Hindin MJ. The effects of unintended pregnancy on infant, child, and parental health: A review of the literature. Stud Fam Plann. 2008;39(1):18-38.

32. Morikawa M, Okada T, Ando M, et al. Relationship between social support during pregnancy and postpartum depressive state: A prospective cohort study. Sci Rep. 2015;5:10520.

33. Logsdon MC, Cognac-Griffin D. Social support in the postpartum adolescents: Guidelines for nursing assessments and interventions. J Obstet Gynecol Neonatal Nurs. 2005;34(6):761-768.

34. Dennis CL, Ross L. Women's perceptions of partner support and conflict in the development of postpartum depressive symptoms. J Adv Nurs. 2006;56(6):588-599.

35. Husain N, Cruickshank K, Husain M, Khan S, Tomenson B, Rahman A. Social stress and depression during pregnancy and in the postnatal period in British Pakistani mothers: A cohort study. J Affect Disord. 2012;140(3):268-276.

36. Ludermir AB, Lewis G, Valongueiro SA, de Araújo TV, Araya $R$. Violence against women by their intimate partner during pregnancy and postnatal depression: A prospective cohort study. Lancet. 2010;376(9744):903-910.

37. Satoh A, Kitamiya C, Kudoh H, Watanabe M, Menzawa K, Sasaki $\mathrm{H}$. Factors associated with late post-partum depression in Japan. Jpn J Nurs Sci. 2009;6(1):27-36.

38. Segre LS, O'Hara MW, Arndt S, Stuart S. The prevalence of postpartum depression: The relative significance of three indices of social status. Soc Psychiatry Psychiatr Epidemiol. 2007;42(4):316-321.

39. Mayberry LJ, Horowitz ME, Declercq E. Depression symptom prevalence and demographic risk factors among US women during the first 2 years postpartum. J Obstet Gynecol Neonatal Nurs. 2007;36(6):542-549.

40. Jin P, Mori E, Sakajo A. Risk factors, cross-cultural stressors and postpartum depression among immigrant Chinese women in Japan. Int J Nurs Pract. 2016;22(Suppl 1):38-47. 